\title{
A circular economy for electric vehicle batteries: driving the change
}

\author{
Jyoti Ahuja, Louis Dawson and Robert Lee \\ Department of Law, University of Birmingham, Birmingham, UK and \\ Faraday Institution, Quad One, Science and Innovation Campus, Didcot, UK
}

\begin{abstract}
Purpose - With the UK's accelerating plans to transition to electric mobility, this paper aims to highlight the need for policies to prepare for appropriate management of electric vehicle (EV) lithium-ion batteries (LIBs) as they reach the end of their life.

Design/methodology/approach - This is a regulatory review based on projections of EV LIBs coming off the market and associated problems of waste management together with the development of a servitisation model.

Findings - Circular economy in EV LIBs is unlikely to shape itself because LIB recycling is challenging and still in development. LIB volumes are insufficient for recycling to be currently profitable, and a circular economy here will need to be driven by regulatory intervention. Ignoring the problem carries potentially high environmental and health costs. This paper offers potential solutions through new EV ownership models to facilitate a circular economy.
\end{abstract}

Research limitations/implications - The authors suggest a new EV ownership model. However, despite environmental benefits, re-shaping the fundamentals of market economies can have disruptive effects on current markets. Therefore, further exploration of this topic is needed. Also, the data presented is based on future projections of EV markets, battery lifespan, etc., which are uncertain at present. These are to be taken as estimates only.

Originality/value - The paper proposes regulatory interventions or incentives to fundamentally change consumer ideas of property ownership for EVs, so that EV automotive batteries remain the property of the manufacturer even when the consumer owns the car.

Keywords Circular economy, Battery leasing, Battery regulation, Circular economy in EV batteries, EV policy, Lithium ion batteries

Paper type Research paper

\section{Introduction}

Global carbon dioxide $\left(\mathrm{CO}_{2}\right)$ emissions have increased steadily in the past few decades, and human fossil fuel consumption is fundamentally linked to global warming (Zhao et al., 2019). Further, fuels derived from petroleum that have been the main source of energy in the transport sector (for example, for fuelling traditional internal combustion engine automobiles) contribute significantly to air pollution, which is now recognised as the major global risk factor for ill-health and death (Apte et al., 2017). The recent emergence of lithium-ion batteries (LIBs),

(C) Jyoti Ahuja, Louis Dawson and Robert Lee. Published by Emerald Publishing Limited. This article is published under the Creative Commons Attribution (CC BY 4.0) licence. Anyone may reproduce, distribute, translate and create derivative works of this article (for both commercial and noncommercial purposes), subject to full attribution to the original publication and authors. The full terms of this licence may be seen at http://creativecommons.org/licences/by/4.0/legalcode

Funding: This work was supported by the Faraday Institution [grant number FIRG005, FIRG006].

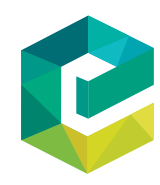

Journal of Property, Planning and Environmental Law Vol. 12 No. 3,2020 pp. $235-250$ 
JPPEL 12,3

which are the main power source for electric and electronic equipment such as mobile phones and are increasingly becoming the power source of electric vehicles (EVs), provides a significant opportunity to decrease fossil fuel consumption and reduce pollution. The move to electric mobility is now key to the global effort to tackle climate change. In the UK, the government is committed, under the Paris Accord (Paris Agreement to the United Nations Framework Convention on Climate Change, 2015) and the Climate Change Act, 2008 (s1(1)), to reduce greenhouse gas emissions by $80 \%$ of 1990 levels by 2050. The UK Government's 2018 Road to Zero strategy (Department of Transport, 2018) has committed to phasing out the sale of all new petrol and diesel (internal combustion engine, or ICE) vehicles by 2040. The Committee on Climate Change, however, now recommends that this deadline be brought forward to 2035 to meet the target for road transport emissions to be near-zero by 2050 (Committee on Climate Change, 2019). Reports indicate that the Government plans to move this deadline to 2035, and possibly even further forward to 2032 (Jolly, 2020). In 2019 the UK Government set a new target that will require the UK to bring down all greenhouse gas emissions to net zero by 2050 (Department for Business, Energy and Industrial Strategy and The Rt Hon Chris Skidmore, 2019).

Alongside the potential benefits of this transition, however, is a danger that some of the environmental gains from the transition to electric mobility could be diluted if we do not adequately plan for the sustainable and safe management of $\mathrm{EV}$ batteries at the end of their first life in an EV. Because of the power needed to propel an EV, these batteries will still contain significant residual capacity (around $80 \%$ of their initial capacity, according to current estimates) (Ahmadi et al., 2014, pp. 64-74) even after they are no longer able to provide vehicle traction. In addition, LIBs also contain valuable and critical materials (such as cobalt, lithium and nickel), many of which are at risk of supply shortfalls in the near future. Extraction of some of these metals has raised environmental and ethical concerns in countries where they are mined (Hirst et al., 2018).

Circular economy goals demand that the residual power and valuable material components remaining in the batteries when they reach the end of their first life in an EV are used to the fullest possible extent before the battery is disposed of. A sustainable value chain for EV batteries is one which reduces environmental impacts and avoids the depletion of natural resources to maintain an environmental balance while promoting economic growth (Hill et al., 2019, p. 119). A battery economy which has moved away from a traditional linear (take, make, use and throw) supply model, to one which is fundamentally circular (take, make, re-use/repurpose, recycle) will enable the battery economy to become resource efficient, thus ensuring that maximum potential is harnessed from an EV battery (see 3(a) below for further discussion of circular economy models in batteries). This paper describes the current obstacles to a sustainable value chain for LIBs, and makes the case that legal and policy interventions are necessary to steer the market in this direction. In particular, it is suggested that rethinking notions of property and ownership of EVs, so as to encourage the uptake of servitisation models for EV batteries, could contribute significantly to achieving a circular economy and efficient end-of-life (EoL) management system for batteries.

Recycling of LIBs is challenging for several reasons, including: the lack of standardisation of LIB design and chemistry; recycling processes that are still in development; and inadequate recycling infrastructure (discussed in 2(b) below). Furthermore, LIBs contain several hazardous materials, and due to the high amounts of residual power contained in them, can be vulnerable to explosions, fire and toxic gaseous emissions, especially if damaged. Thus, they also pose a significant threat to human health and the environment if not managed or disposed of correctly. 
EVs represent a new application of LIB technology and will constitute LIB application at Electric vehicle a scale not previously seen in the UK, due to the large size and anticipated volumes of EV batteries. So far, most LIBs that have needed to be managed after being discarded from first use in the UK have been smaller portable batteries used in electronic equipment such as laptops, mobile phones and power tools. As this is a relatively recent technology, most EV batteries in circulation in the UK have not yet reached the end of their first life, although EV manufacture and sales are growing quite rapidly. The scale of the problem will rise in the next few years [the projected volumes of EV LIBs to be processed are discussed at 2(a)]. LIB recycling processes are still in development and recycling efficiencies are still relatively low. Within the UK, there are companies that collect and sort LIBs and then export them to countries that have recycling facilities, since there is currently no UK infrastructure for LIB recycling, and many regulatory and policy uncertainties remain regarding second-use of LIBs (explored in Section 4). UK EoL vehicle management companies, who have been accustomed to handling only one battery type (i.e. lead-acid), will need to develop systems for managing a wide range of $\mathrm{EV}$ battery configurations and chemistries in the near future.

This paper will discuss why changes to the legal frameworks applying to the management of LIBs when they are removed from EVs are needed to reduce safety risks and facilitate effective takeback and EoL management. A battery circular economy for LIBs is unlikely to arise without policy intervention, we contend. Thus, innovative legal and regulatory frameworks (which might take the form, for example, of incentivising potentially beneficial business models) are now essential for supporting the EV transition. Our primary aim is to propose a potential regulatory solution, which involves re-valuating ownership models for EVs and EV batteries. We advocate the benefits of a servitisation model, such that manufacturers retain ownership and control of EV batteries through battery leasing to replace the current model of battery ownership vesting in the owner of the vehicle. Servitisation is an increasingly common form of business model in which manufacturing companies retain ownership of assets throughout their lifetime such that the use or the function of a product is sold rather than the product itself, with the customer paying to ensure the availability and reliability of the service. Although this business model is more commonly pursued to enhance consumer convenience or gain competitive advantage (Sacciani, 2012, pp. 336-354), here we advocate that its greatest benefit would be to improve the safety, sustainability and circularity of EV battery management.

We structure our argument for regulatory changes by first outlining the context: in Section 2, we describe the current challenges, including the imminent volumes and scale of the problem. We discuss various optional EoL strategies for EV LIBs, such as recycling and second-use, and explain why safety and sustainability of both these routes are much more complex than for traditional automotive (ICE) batteries. Section 3 discusses critical material shortages and circular economy dilemmas in this area, which make planning and policy interventions imperative. Section 4 discusses the current battery regulatory framework and its inadequacies in addressing some crucial challenges. We will argue that the Batteries Directive (Directive 2006/66/EC), which is amongst the primary pieces of legislation regulating the environmental performance and the collection, treatment and recycling of waste batteries is no longer appropriate for managing the EoL battery challenges of the EV transition. Finally, in Section 5, we explain our regulatory solution based on re-valuating EV LIB ownership to move towards a greater role for battery servitisation, such that manufacturers retain ownership of EV batteries through battery leasing to replace consumer ownership. We explain why this could help to enhance battery life and value, through better maintenance and control over battery usage. Such a model would also help EoL management as it would improve LIB collection and take-back rates, reduce risks of 
JPPEL 12,3

unsafe or illegal disposal and make more batteries available for recycling and re-use. Crucially for circular economy goals, it would also encourage eco-design of EV LIBs as manufacturers would stand to benefit directly from designing batteries that are easier to remove and disassemble (difficulty removing and disassembling EV batteries is a major barrier to LIB recycling at present). Further, this would also assist to reduce upfront costs of EVs, which would enhance EV uptake; ensure that collected batteries are in a relatively good or diagnosable state of health, thus promoting circular economy values and making it easier for manufacturers to decide whether the lifetime of the battery could be extended before being recycled.

\section{End-of-life management of electric vehicle lithium-ion batteries: the challenges} 2.1 Scale of the problem: projected volumes

Future estimates of global EV stocks vary, ranging from 50 million (Trafigura Research Report, 2018) to a possible 130 million by 2030 (International Energy Agency, 2018). The number of licensed ultra-low emission vehicles on UK roads is rising steadily year-on-year. Projections from the National Grid suggest that the stock of EVs in the UK could reach between 2.7 and 10.6 million by 2030, rising to as much as 36 million by 2040 (National Grid, 2018). If the phase out date for new petrol/diesel sales is brought forward to 2035 or 2032, as currently being contemplated by the Department for Transport (BBC News, 2020), the UK stock could be even higher by 2040 .

The Faraday Institution ReLiB Project estimates that if the first life of an EV battery ranges from 8 to 10 years, the UK will need to manage or reprocess around 16,650 tonnes/ year of EoL EV battery packs (or around 8,000 tonnes/year of cells/modules) (The Faraday Institution, ReLiB project) by 2028. Globally, the tonnage of spent LIBs discarded by 2030 is estimated to range from 11 million tonnes (Trafigura Research Report, 2018) to 16 million tonnes. The UK does not currently have any LIB recycling facilities, and relies on transhipment to other European Union (EU) recycling facilities to meet recycling targets for the relatively small volume of EoL LIBs largely from waste electronic and electric equipment that need managing at present. Transhipment is not, however, a viable long-term solution as LIB volumes increase; especially as options to tranship to Europe are limited by the available infrastructure. Further, there remains uncertainty surrounding the complexity and cost (including tariff costs) of transhipment post-Brexit (the UK is currently part of the EU, but from 1 January 2021, subject to any extension of the implementation period, it will be treated as a third country for the purposes of Regulation (EC) No 1013/2006 of the European Parliament and of the Council of 14 June 2006 on shipments of waste). Currently, some UK manufacturers do export spent LIBs to continental European facilities for recycling, but gate prices are very high: partly, because these facilities are insufficient to cater to the level of need we will be facing in the coming decade. At present, the largest EU battery recycling facility (Umicore in Belgium) can process just 7,000 tonnes per year (Ahuja and Lee, 2019). However, the UK alone will generate more spent EV LIBs than the overall capacity of this facility: as mentioned earlier, estimates suggest that by 2028, the UK will need to process over 8000 tonnes/year of obsolete cells/modules from EV battery packs. Efficient systems for managing LIBs from EVs are imperative if their widespread use is to be sustainable, and therefore it is important that UK policies and regulations facilitate the establishment of LIB recycling facilities in the UK.

Various options are currently being actively explored for managing EoL LIBs: these include recycling and second use. Second use could include re-using the battery again in an EV (here, termed "re-use"), or redirecting the LIB for a different use such as stationary 
storage applications, (here, termed repurposing). Both re-use and repurposing require Electric vehicle challenges to be overcome for widespread application to be feasible.

batteries

\subsection{Lithium-ion batteries recycling: the challenges?}

EV LIB recycling is presently much more complex than recycling of lead-acid batteries used in traditional ICE automotives. LIBs are more powerful and variable in technology and chemical composition than ICE batteries. Whereas batteries used in ICE vehicles (which are only used to power the electrical circuits) have evolved, over time, almost uniform and standardised chemistries, lithium-ion is not one single technology but a common denominator for several different chemistries based on a similar principle (Trafigura Research Report, 2018, p. 8). Unlike ICE batteries, no standard form or chemistry has emerged yet for EV batteries, and no LIB recycling technology has been deployed as yet in the UK (Ahuja and Lee, 2019). The number of EVs reaching EoL in the UK is still relatively small, so the volume of batteries to be processed is insufficient for establishing a commercially viable operation. Volumes (and potential profitability) will rise in the future as more EV batteries start reaching the end of their first life. The complex planning needed to set up suitable facilities for the safe management and recycling of LIBs necessitates that this imminent need is addressed and that relevant infrastructure is put in place before volumes rise to unmanageable levels. Further, LIB recycling processes are still in the developmental stage and are far from achieving the recycling efficiencies of lead-acid batteries. Present processes are reported to achieve, for example, a recycling efficiency of around $50 \%$ : which means that only around half of the materials contained in the cells can be recovered (Tytgat, 2013). This is in contrast to the over $90 \%$ recycling efficiencies for most traditional lead-acid automotive batteries.

\subsection{Challenges of lithium-ion batteries second-use}

The viability of second use in energy storage applications should be evaluated before recycling to extract maximum value from EV LIBs. Second use could include re-use (using the battery again in an EV after repair/refurbishment) or repurposing it for a different application such as stationary energy storage. The question of whether re-use or repurposing is feasible or not is heavily dependent on the condition and state of health of the battery (Hill et al., 2019, pp. 19-20).

Battery repurposing refers to redeployment of the battery for a different purpose from that for which it was originally designed. Due to the significant residual capacity contained in LIBs even after they can no longer effectively power an EV (usually around $80 \%$ of the nominal capacity), there is high interest and potential for less energy-demanding applications, e.g. grid back-up and uninterruptible power supply to help combat the intermittency of renewable energy (Bobba et al., 2019, p. 280). A recent European Commission stakeholder consultation indicated that "a significant share" of the batteries reaching EoL within a vehicle would be suitable and could be used for such repurposing, depending on their state of health (Hill et al., 2019, p. 26).

Second use of spent EV batteries is challenging for a number of reasons. There are concerns around safety of second use, and uncertainties about how the first user may have handled or maintained the battery. Some manufacturers have indicated a reluctance to engage with re-use and remanufacture. This is in part because of potential risks, as the feasibility for re-use depends to a great extent on the stewardship and usage during first life. For example, if an EV owner owns their battery and uses it until it has reached an unacceptable state of health, then it may not be suitable for repurposing (Hill et al., 2019, p. 26). A proper assessment of state of health needs to consider aging/stress in the first life 
JPPEL 12,3

(which could influence safety), as well as information about battery usage/charging history. Under traditional vehicle ownership models, where a purchaser owns the car as well as its battery, manufacturers would have limited control over how the first user uses and services the car. Even though there will be access to information contained in the Battery Management System, the element of control or interest in the maintenance, repair and EoL management of the battery system is lower than in a model where the vehicle manufacturer owns and maintains the battery. There are also concerns about potential reputational damage if a second life battery turns out to be of sub-optimal quality. As well as concerns about general state of health, it is also possible that initial owners of these batteries may continue to use them well below the $80 \%$ capacity which is widely recommended as the point at which an EV should have its battery replaced. This is sub-optimal use of the battery pack and will reduce the number of cells available for effective second use, which will have an adverse impact on the circular economy model. This suggests that: "the uncertainties in quality, time and quantity of the returns are a great challenge for a successful remanufacturing business model" (Kampker, 2016).

There are also other challenges which impact on the feasibility of second-use, such as unclear regulations and technical challenges. A number of commentators express concerns about dangers arising from the flammable and explosive nature of the material as well as toxic gas emissions in the event of an explosion (Commission for Environmental Cooperation, 2015). However, recent advances have addressed some of these health and safety issues, for example through improvements in the initial battery design. Some manufacturers are improving the design of the battery pack, making it easier to open the pack so the components are less risky to replace (Hill et al., 2019, pp. 21-22).

We contend that technological improvements, in combination with regulatory measures that give manufacturers greater control over battery use and maintenance, could go a long way in enhancing safety as well as the economic feasibility of LIB second-use.

Schemes that give manufacturers access to reliable information about battery usage/ maintenance will facilitate efficient resource allocation by reducing battery damage through over-use, and by facilitating more informed decision-making. This may be very helpful in addressing manufacturer anxieties about second-use applications. Our proposed solution based on a battery servitisation model would not only help the take-back of more EV batteries but also bring back batteries that are in a better state of health and thus potentially more useful for re-use purposes.

\section{Circular economy dilemmas at the end of first life}

3.1 Circular economy objectives and critical materials shortages

Present EV battery chemistry uses a varied and expansive list of materials, and no standard battery chemistry type has been developed by the automotive industry. This is partly because EV batteries are new to the market and manufacturers need to experiment with chemistry to achieve a balance between range and power and gain competitive advantage. However, other restricting factors include the price, availability and potential environmental harm attaching to different materials. Current EV batteries typically contain materials such as cobalt and graphite in different quantities, both of which are classified as critical materials in the EU (European Commission, 2018). Criticality here indicates that the material is essential to the development of the EV market, but there could be insufficient quantities of it available to support its predicted future demand (Spears, 2015): this could be due to geographical or geo-political issues, price volatility or ethical and environmental concerns.

As reliance on critical materials grows for EV batteries within both the UK and the EU, so too does the importance of transitioning from a linear economy which takes, makes, uses 
and discards to one which is fundamentally circular. An economy which is circular seeks to keep resources in use so that maximum value can be extracted from them, and waste can be kept to a minimum. The metal components of an EV battery can be continually recycled. They therefore fit easily into a circular economy which enables resources to travel in a circular motion through the key life cycle stages continuously, in a looped cycle, thus reducing the need to extract virgin raw materials (Figure 1). If EV batteries were leased, this could enhance the management of batteries when they are removed from the vehicle facilitating traceability, repair, re-use, repurposing and recycling. This will minimise reliance on critical materials, and further enhance the development of the battery circular economy.

\subsection{Managing lithium-ion batteries at the end of first use: recycling or re-use?}

Second use of EV batteries once they reach a point where they are no longer able to power an $\mathrm{EV}$, but still retain considerable amounts of power, seems a promising way forward to effectively harness residual value and capacity. Both the legislative framework (e.g. the Waste Framework Directive (Directive 2008/98/EC) and the literature (Bobba et al., 2019, p. 280) concur that in general the extension of product lifetime through re-use or remanufacturing contributes to the circular economy theory that supports the minimisation of waste and better resource management. Re-use (i.e. using the battery again in an EV) is preferable to repurposing (i.e using the battery in an alternative application; such as a storage battery to back-up the grid) as it should be less energy and resource intensive to make the battery fit again for the same purpose, compared with the effort and time required to remanufacture (Hill

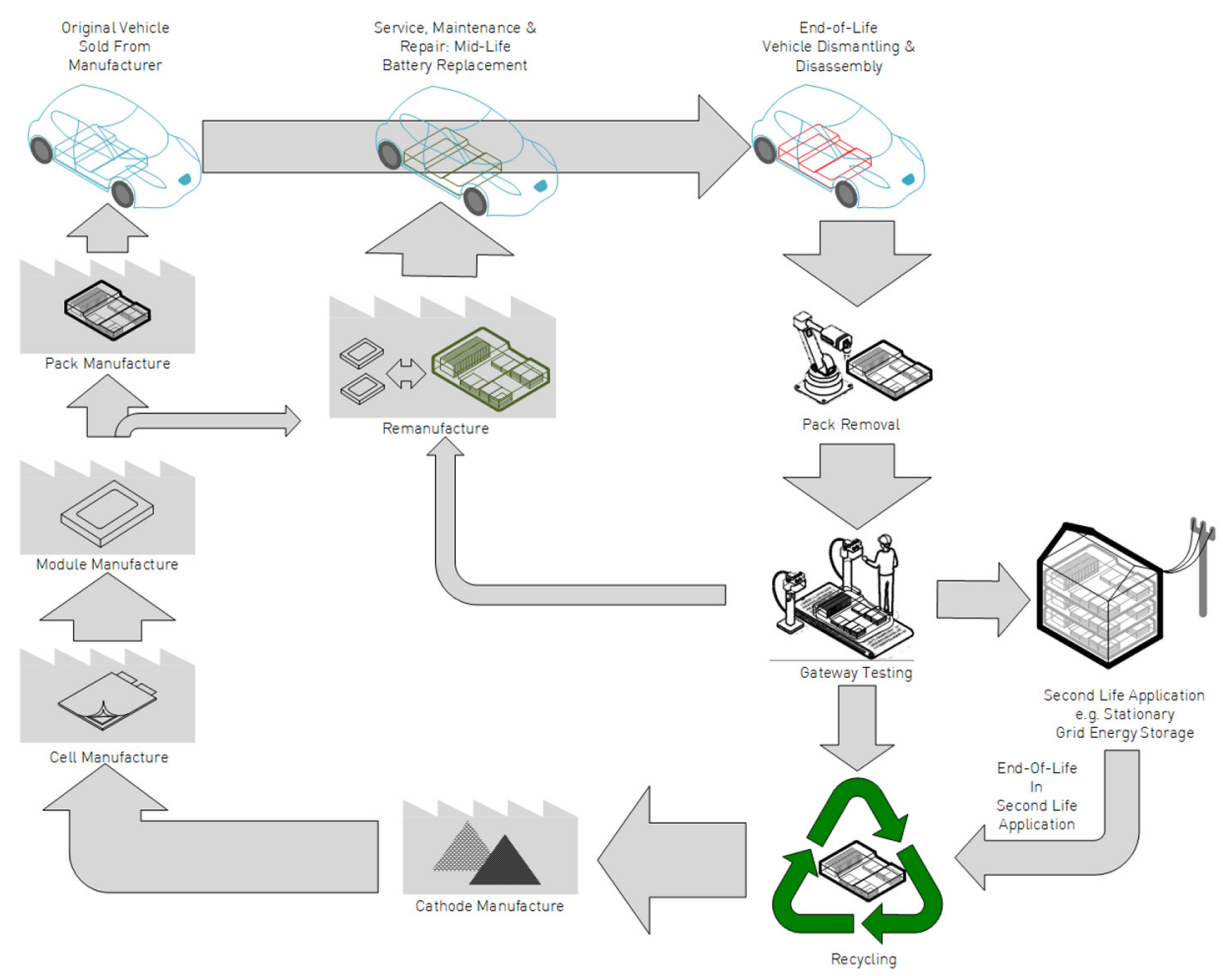

Electric vehicle batteries 
JPPEL 12,3

et al., 2019, pp. 20-22). Where repair and re-use in another EV is not feasible, the EU's waste hierarchy (Directive 2008/98/EC)) would generally view repurposing (rather than direct recycling) as the more sustainable strategy. However, the relative sustainability merits of repurposing versus recycling are not so clear where EV LIBs are concerned.

It is important to remember that despite the benefits, repurposing of EV LIBs would interrupt the type of supply loop envisioned by the circular economy objectives and Extended Producer Responsibility (EPR), and will delay recycling. Direct recycling, instead of repurposing, would bring some these high-demand critical materials back into the value chain faster. The benefits derived from repurposing must therefore be balanced against the impact of the delay in the availability of the materials contained for recycling. The commercial case for setting up and improving recycling infrastructure and processes is currently fragile, as EoL LIBs have not yet started to emerge in large enough numbers for recycling to be sufficiently profitable, and the relatively small volumes can currently be exported for recycling. Presently, neither market conditions nor regulations are stimulating vehicle manufacturer engagement in developing recycling infrastructure in the UK- this is not the case in the EU. This is potentially problematic, because, as discussed earlier, only those LIBs that are in a sound state of health will be suitable for repurposing. Recycling infrastructure is needed, therefore, if the UK is not to be reliant on exporting this material that is difficult to transport and is likely to face regulatory and/or cost barriers.

Further data is still needed to decide whether best circular economy benefits could be achieved through direct recycling of the critical materials contained within LIBs. While our new regulatory proposals for battery ownership would mainly help to extend battery life, and facilitate re-use and repurposing, we suggest that it would also help to facilitate improved recycling efficiencies through greater takeback and collection rates. Thus, all of the optional routes for managing EoL LIBs would see some benefit from a battery servitisation model (Section 5).

\section{Current UK regulatory landscape for batteries}

The key policies regulating the market include the Batteries Directive (Directive 2006/66/ EC), the End of Life Vehicles Directive (Directive 2000/53/EC - currently under review) and the Registration, Evaluation, Authorisation and Restriction of Chemicals Regulation (Regulation (EC) 1907/2006) and Regulation (EC) No 1272/2008 on classification, labelling and packaging of substances and mixtures). Together these policies regulate the use of hazardous substances, environmental performance of batteries throughout their lifecycle and the collection, treatment and recycling of waste batteries (including targets for collection rates and for recycling efficiencies).

Currently, EoL EV batteries are exported from the UK to the EU for recycling. In time, this may become problematic (due to issues around increasing volumes, processing capacity, transport, safety and waste shipment regulations) (Ahuja and Lee, 2019). As a result of the rapid uptake of EVs in China, the Chinese Government has introduced EV battery recycling regulations (Hou, 2019) and studies illustrate that recycling LIBs will be a significant global business (Melin, 2018). UK EoL vehicle management companies, who have been accustomed to handling only one battery type (i.e. lead-acid), will need to develop systems for managing a wide range of $\mathrm{EV}$ battery configurations and chemistries in the near future, depending on contractual arrangements for waste management.

The current policy landscape in the UK relies on EU legislation to promote a sustainable EV battery value chain (notably, there is significant uncertainty about what happens postBrexit, at the end of the UK transition period from the EU, as no clear decisions have yet been taken on the way forward in this area). A sustainable value chain for EV batteries can 
be defined as one which reduces environmental impacts and avoids the depletion of natural Electric vehicle resources to maintain an environmental balance (Hill et al., 2019, p. 119).

The Batteries Directive (Directive 2006/66/EC) regulates the collection, treatment and recycling of waste batteries by extending the producers responsibility. EPR legislation, which acts as an extension of the "polluter pays principle", has two main aims: first, to reduce the immediate environmental impact of the product by mitigating the products' harm at its EoL, and second, to influence the design of a product (Directive 2008/98/EC). EPR legislation passes responsibility for the whole life-cycle (but focusing particularly on EoL) of a product away from municipalities and transfers it to the producer of the targeted product. This results in the producer having physical and/or financial responsibility for their product.

Batteries are presently classified into three different categories within the Batteries Directive: portable, automotive and industrial batteries. Rather oddly, the batteries that manage the energy used to drive EVs are currently classified as "industrial" rather than "automotive" batteries. The Directive pre-dates the rapid transition from ICE to EV and was drafted before LIB EVs were in widescale use: in this legislation, "automotive batteries" refers to the $12 \mathrm{~V}$ lead-acid battery used to provide the electric services. Thus, EV LIBs do not fall within the definition of "automotive" batteries, as this technology was not available in the market at that time. One effect of $\mathrm{EV}$ batteries being classified as "industrial" is that producers are not currently subject to any formal collection and recycling targets (aside from any relevant efficiency targets). Therefore, "industrial" producers are in a less onerous position than that of the producers of lead-acid batteries used in traditional ICE vehicles. EV battery producers [i.e. those who place batteries [...] on the market for the first time [...] on a "professional basis" (Directive 2006/66/EC, Art. 3 (12))] are required, under the Batteries Directive, to "takeback" the spent vehicle battery from the end-user (Directive 2006/66/EC, Art.8 (3)). Thereafter, they must ensure that the batteries are treated and recycled. It is notable that EV producers do not have to meet any take-back target, apart from being obliged to give end-users information about the existence of take-back schemes and the harmful effects of incorrect disposal (Directive 2006/66/EC, Art. 20). Nevertheless, once a producer has taken-back an industrial battery, they are under an obligation to put the battery through treatment and recycling (Directive 2006/66/EC, Art. 12); there is a complete prohibition on placing industrial batteries in landfill or incineration (Directive 2006/66/EC, Art.14). Any net cost arising from the collection, treatment and recycling of batteries (Directive 2006/66/EC, Art.16), as well as information campaigns, (Directive 2006/66/EC, Art. 16(3)) is financed by the producer.

We argue that the current 2006 battery regulations are inadequate to deal with the new EV landscape, and arguably are no longer "fit for purpose" to support effective use and management of EV LIBs. A recent review of the Directive acknowledged this point, and also raised the possibility of a redraft (European Commission, 2019). Within the Directive, there are several gaps with regard to safe storage and transport of LIBs. The anomalous classification of $\mathrm{EV}$ batteries as industrial rather than a specific category means that there is little to no regulatory demand or incentive for producers of EV LIBs to facilitate EoL management, or indeed to design EV LIBs such that they are easier to re-use or recycle. Moreover, unclear regulations around second use (including the lack of definitional clarity about what constitutes re-use/repurposing) (Ahuja and Lee, 2019) increases producers' reluctance to engage with this. Despite an increasing interest in reusing batteries, studies highlight that manufacturers feel there is a need for "governmental incentives on battery reuse" (Bobba et al., 2018, p. 20). 
JPPEL 12,3

\section{New electric vehicle ownership models: battery servitisation and its potential benefits}

One significant question in relation to regulation is the extent to which it can influence business models in favour of those which promote safe and effective EoL management. We suggest that an EV battery servitisation approach would greatly help the sustainable management of batteries at the end of their first life. We therefore propose policy interventions to promote $\mathrm{EV}$ ownership frameworks such that the manufacturer retains ownership of the EV battery, even when a consumer owns the rest of the car. Servitisation is an increasingly common form of business model in which manufacturing companies retain ownership of assets throughout their lifetime such that the use or the function of a product is sold rather than the product itself, with the customer paying to ensure the availability and reliability of the good.

This, we contend, could promote safer and more efficient second use, thus increasing the incentive for producers to engage with developing such applications. It would also enhance recycling by increasing collection and takeback of spent EV batteries, as well as promote design for recycling. A further advantage is that this model could help the environmental goal of increasing $\mathrm{EV}$ uptake. A number of studies have found that the high initial purchase price of EVs is amongst the most significant barriers to EV uptake (Office for Low Emission Vehicles, 2015, p. 44). The battery is a very expensive component of an EV; thus, the initial purchase price would be significantly reduced when the cost of the battery is removed from this, as would happen under a battery leasing scheme. Thus, another advantage of a servitisation model is its potential to reduce the initial outlay on an EV, thereby promoting more rapid uptake of electric mobility. Under this model, the battery leasing cost can be regarded as a running cost (along with the cost of charging), which could transform consumer perception of the economics of buying an EV, and provide a more level playing field for EV markets. The up-front cost of the EV (minus battery) would be directly comparable to the cost of a conventional vehicle, while the running costs (battery lease + electricity consumption) would be directly comparable to the cost of petrol/diesel.

Current battery leasing schemes, trialled by companies such a Renault, provide an effective example of how such a regulatory model could work in practice. Renault offers a battery leasing scheme for their ZOE models to certain customers: the "Z.E. flex battery hire agreement" (Hill et al., 2019, p. 137). Under this arrangement, customers purchase the vehicle but lease the battery, with the price per month linked to annual mileage. RECHARGE (the industry association for advanced rechargeable and lithium batteries in Europe) explains that this allows manufacturers to retain control over the battery value chain, including decisions about whether and when to repair or replace the batteries (Tytgat and Tomboy, 2017). However, unfortunately there has been little consumer uptake of this scheme, for reasons that are unclear. This further strengthens our call for regulatory drivers or incentives towards servitisation. Leading vehicle manufacturers in Japan (e.g. Nissan and Honda) are actively developing systems for re-use, repurposing and recycling (Loughran, 2018).

As discussed earlier in section 1(c), the feasibility of LIB second-use is dependent to a large extent on the state of health of the battery when it reaches the end of its first life. Moreover, diagnosing battery state of health can be complex and difficult: knowledge about the usage history of a LIB can greatly help to assess state of health. However, in traditional models of ownership, where a purchaser owns the car and all its components, the battery is ultimately in the control of the user. The manufacturer thus has little influence over battery management before the used battery is returned to them (Hill et al., 2019). The operation of battery packs is controlled by the Battery Management System (BMS). These are now more 
sophisticated than early versions and can collect, store and transmit data on the battery operation and condition. the vehicle manufacturer will have access to this data which they consider to be proprietary. However, they could use this information, or make it available to authorised parties in order to facilitate the evaluation of the battery when it is removed from the vehicle. A servitisation model could help vehicle manufacturers engage better with EoL management of the battery pack, including re-use, which some manufacturers are currently reluctant to develop. Ford, for example, expressed caution about re-use, indicating in a 2014 presentation that their approach is to "de-energise" (or discharge) and then recycle these batteries, with no re-use allowed (Hill et al., 2019, p. 23).

Further, where a purchaser owns all components of the car, initial owners of these batteries may use them well below the $80 \%$ capacity which is widely recommended as being the time when an EV should have its battery replaced. Continued EV use beyond this point can irreversibly damage cells and components so that second use may no longer be feasible. However, when the manufacturer owns the battery, they can more easily ensure that it is replaced when the capacity nears $80 \%$, and as such it will be more readily re-purposed. Therefore, a battery servitisation model allows the manufacturer greater control of the battery, which thereafter facilitates the take-back, re-use/repair and recycling of batteries, while also encouraging design for recycling.

At the very least, battery leasing would help manufacturers to run more regular diagnostic checks on EV batteries, use BMS data to detect faults, predict failure and facilitate preventive maintenance. It would also allow the manufacturer to decide the point at which it would be cost effective to replace components, or the entire battery pack. Servitisation would clarify ownership/responsibility and faciltate decisions about second life and recycling; although we concede that such a model will require more research not only on mechanisms for implementation but also any foreseen industry effects (such as the possible effect on consumer choice and on independent garages).

The revision of EV ownership models presented by this paper could enhance the producer's ability to retain value via ensuring efficient take-back. Inherently, leases contain a definitive termination date for which the consumer will be obligated to return the battery to the manufacturer. Once in possession of the battery, producers of "industrial" batteries are required to treat and recycle the battery at their own cost. Such an ownership model could support the facilitation of a circular economy, which both the EU [through their Circular Economy Package legislation (European Commission, 2015)] and England [through the English Waste Strategy (DEFRA, 2018)] are hoping to achieve in the near future. With this in mind, manufacturers could seek to develop practices that will enable the maximisation of battery value through changing the ownership model to facilitate a closedloop cycle of battery components. This will decrease reliance on virgin critical materials, therefore allowing for components to continuously flow from manufacture to consumer and back to manufacturer to start the process again. As a result, while the new ownership models as proposed in this paper could in some ways place greater burdens or responsibility on manufacturers, it could also constitute an opportunity to enhance profitability by ensuring that more LIBs come back to manufacturers for re-use, repurposing or recycling. Additionally, the servitisation model could offer other unseen environmental benefits for high-value and environmentally costly LIBs. Regular and reliable maintenance and servicing may also, for example, lead to better lifetime outcomes by prolonging the first life of an EV battery: manufacturers as owners of the battery would have every incentive to extend the life of the battery as much as possible, as well as to consider EoL management right from the outset by designing batteries that are easier to remove and disassemble (and thus easier to recycle or re-use). Although these gains may look marginal at first glance e.g.
Electric vehicle batteries 
JPPEL 12,3

by adding a few months to the overall life of the battery, the cumulative effect of these could be significant, based on resource flow.

Notions of ownership pervade waste management law. For the most part we assume that where goods have been acquired for value there will be adequate incentives to safeguard and exercise custody over those goods. However, at the point at which goods are thought no longer to be of value and such that the holder forms an intention to discard those goods or does so discard them (Article 3(1) Waste Framework Directive (Directive 2008/98/EC - as amended) we will regard such goods as waste. This is because of the concern about their fate lest in discarding these goods, harm is caused to human health or the environment. These concerns may relate to abandonment, littering, fly-tipping or to more direct harm caused by the leaching of metal deposits into environmental media. In contrast to this potential for harm, an end of life EV LIB is potentially of value both in terms of its material components but also in relation to its potential for a second purpose.

As is demonstrated in this paper, at the point that an EV LIB leaves the vehicle, there are reasons to be concerned about leaving its fate entirely to an unregulated market. Undesirable second use, illegal dumping, unwanted processes of waste transhipment outside of the UK, and questions of future safety might require intervention in the market by way of regulation. Like any regulatory intervention, however, policing and enforcement may mean the deployment of considerable public resources and may be beset by regulatory failure. We see an example of this in the apparently simple model for EoL vehicles in the European market. There are as many as 3.5 to 4.5 million vehicles per year leaving the European market with "unknown whereabouts" and with no certificate of destruction as required under regulation. These "ghost" vehicles are deregistered in the Member States but are not reported either as legally treated EVs or as legal exports as second-hand vehicles. (Report of the Commission on the implementation of Directive 2000/53/EC on EoL vehicles, 2017). This illustrates that take back schemes can be difficult to police where they rely of some form of return or collection. In a servitisation model, however, the ownership and the responsibility remain with the vehicle manufacturer overcoming any deficit in the take back model thereby supporting circularity (Spring and Araujo, 2017).

The servitisation model is increasingly seen as "one possible enabling factor of the circular economy" (de Estarrona et al., 2019). The repair (or re-use) of (usually high value) products during their lifetime, together with the accessibility to the product to remanufacture at the EoL, is seen as an increasing attraction of this model. It runs in a very different direction to that of public service provision of waste collection. It passes responsibility away from the public to the private sector, in an extended manner to the producer of the goods. However, rather than simply seeing this as the passage of a burden to the private sector, there is increasing recognition (Bressanelli, et al., 2018) of the value of the component parts and materials that may make this retained ownership model attractive, thereby negating the need for costly and troublesome EoL regulation.

This involves a philosophical change in the way in which we conceptualise waste. Rather than viewing waste handling as the problematic combatting of pollution from waste, it might be viewed instead as a potentially profitable opportunity for the further extraction of value from material flows, to allow an extension of profit from the goods placed on the market. EU law has been slow historically to grasp this fundamental. In a whole series of cases on waste classification, it has stuck dogmatically to the need to regulate discarded materials long past the point at which they have regained economic value (Lee and Stokes, 2008) though recent reforms to the Waste Framework Directive do try to promote the efficiency of resource use, and to the value attached to waste as a resource. (Directive (EU) 
2018/851). Perversely, this raises the question of whether the regulation of waste flows Electric vehicle should be loosened to help establish servitisation models.

We begin from the premise that it would be highly unusual to regulate the business model pursued by industry. Only in very strong cases of market failure might we intervene to demand that goods are provided in a certain form. We do this for prescription medicines for example but only because of the very direct impact of their consumption on public health. It seems unlikely, politically, that a government would mandate that the only form of EV supply must involve a servitisation model for the battery pack. Therefore, we envisage a form of incentive rather than a command and control regulation. Servitisation models are not easily achieved if the companies placing goods on the market do not see additional income flowing from the model. Servitisation business models do increase sales revenues; at the aggregate level, they appear to generate lower profits as a percentage of sales (Neely, 2007). It follows that some incentives towards the adoption of leasing or other forms of servitisation may be useful in driving the shift towards retained ownership and responsibility. Reduction in the red tape of waste management regulation may prove one such incentive, but this can only go so far. There remains a strong public interest in retaining some monitoring of the LIBs throughout their life cycle at least until the point (as may now be the case with lead-acid batteries) that the economic drivers attaching to the recovery of critical materials offers the assurance of responsible handling of critical material flows.

Note, finally, the disruption that may attach to the business models surrounding servitisation. If ownership is retained by a producer, then design for disassembly becomes much more likely, which is a positive benefit. However, then, with increasingly automated disassembly, and with remanufacturing alongside the materials recovery, it may become overwhelmingly likely that the entire reprocessing of EV LIBs is undertaken by one organisation. This might impact on the current structure of metal recycling and waste management enterprises or at the very least leave them as handlers of only low value material flows, as the higher value products remain in closed loops. It is unsurprising, perhaps, that re-shaping the fundamentals of market economies, such as property rights, can have profoundly disruptive effects.

\section{Conclusion}

This paper highlights the potential environmental costs of failing to adequately plan for EoL management of LIBs. We have contended that the cost and complexity of EV LIB manufacture and recycling, coupled with inappropriate battery regulatory frameworks, necessitate more robust and innovative regulatory interventions that are underpinned by circular economy objectives. This, we argue, is imperative to achieve the ultimate environmental objectives of the EV transition. Specifically, we highlight the benefits of a change to traditional ownership models in relation to EVs, such that customers may purchase their EVs but only lease the battery. We thus propose a move to a servitisation model for EV LIBs, so that the battery remains the property of and in the stewardship of the manufacturer. We have outlined the advantages that such a servitisation model may have in ensuring higher rates of take-back of LIBs, which in turn will facilitate safe and efficient management including collection, transport, repair, second life and higher rates of recycling. Such a model could also enhance EV uptake by reducing the initial upfront cost of EVs, extend the lifetime of EV batteries and promote eco-design (design for recycling) of EV LIBs.

There are strong reasons to promote materials' recycling from EV LIBs: rethinking property rights in such products might help drive circularity and maintain the value of the material flows. However, it seems clear that, at least in present market conditions, the development of a complete circular structure for the management of EV LIBs in the UK is 
JPPEL 12,3

unlikely without some form of intervention. Any changes will therefore need to be driven by regulation or incentivisation. While it is difficult to find parallel examples of such regulation which dictate ownership conditions in any other product area, the incentivising of battery leasing or battery servitisation schemes could demonstrate the benefits of this approach. Quite how one shifts business models from sale to service is itself challenging and will require further study. It is less likely to be achieved by command and control regulation than by the re-shaping of market incentives. While this may prove a challenging exercise in regulatory design, the benefits of reconfigured business models based around matching ownership and responsibility may well prove worth the effort.

\section{References}

Ahmadi, L., Yip, A., Fowler, M., Young, S.B. and Fraser, R.A. (2014), "Environmental feasibility of re-use of electric vehicle batteries", Sustainable Energy Technologies and Assessments, Vol. 6, pp. 64-74.

Ahuja, J. and Lee, R. (2019), "The imperative for an effective EV management policy in the UK", working paper, The Faraday Institution ReLiB project, (accessed 31 October 2019) (in draft).

Apte, J.S., Messier, K.P., Gani, S., Brauer, M., Kirchstetter, T.W., Lunden, M.M., Marshall, J.D., Portier, C.J., Vermeulen, R.C.H. and Hamburg, S.P. (2017), "High-resolution air pollution mapping with Google street view cars: exploiting big data", Environmental Science and Technology, Vol. 51 No. 12, pp. 6999-7008, doi: 10.1021/acs.est.7b00891. (accessed 20 February 2020).

BBC News (2020), "Petrol and diesel car sales ban could start in 12 years, says Shapps", available at: www.gov.uk/government/news/uk-becomes-first-major-economy-to-pass-net-zero-emissions-law (accessed 5 June 2020).

Bobba, S., Mathieux, F. and Blengini, G.A. (2019), "How will second-use of batteries affect stocks and flows in the EU? A model for traction Li-ion batteries", Resources, Conservation and Recycling, Vol. 145, pp. 279-291, doi: 10.1016/j.resconrec.2019.02.022. (accessed 5 June 2020).

Bobba, S., Podias, A., Di Persio, F., Messagie, M., Tecchio, P., Cusenza, M., Eynard, U., Mathieux, F. and Pfrang, A. (2018), "Sustainability assessment of second life application of automotive batteries", JRC Technical Reports, available at: https://publications.jrc.ec.europa.eu/repository/bitstream/ JRC112543/saslab_final_report_2018_2018-08-28.pdf (accessed 5 June 2020).

Bressanelli, G., Adrodegari, F., Perona, M. and Saccani, N. (2018), "Exploring how usage-focused business models enable circular economy through", Digital Technologies Sustainability, Vol. 10 No. 3, pp. 639-660.

Climate Change Act (2008), (c.27) [Online] London: The Stationary Office, available at: www. legislation.gov.uk/ukpga/2008/27/contents (accessed 11 August 2020).

Commission for Environmental Cooperation (2015), "Environmentally sound management of end-of-life batteries from electric-drive vehicles in North America", CEC Project Report, available at: www3.cec.org/islandora/en/item/11637-environmentally-sound-management-end-life-batteriesfrom-electric-drive-vehicles-en.pdf (accessed 20 February 2020).

Committee on Climate Change (2019), "Net zero the UK's contribution to stopping global warming committee on climate change", available at: www.theccc.org.uk/publications (accessed 20 February 2020).

Department for Business, Energy and Industrial Strategy and The Rt Hon Chris Skidmore (2019), "UK becomes first major economy to pass net zero emissions law", Gov.uk, available at: www.gov. uk/government/news/uk-becomes-first-major-economy-to-pass-net-zero-emissions-law (accessed 5 June 2020).

Department of Transport (2018), "The road to zero. Next steps towards cleaner road transport and delivering our industrial strategy", Department of Transport, available at: www.gov.uk/dft (accessed 20 February 2020). 
Estarrona, U M D., Seneviratne, D., Villarejo, R. and Galar, D. (2019), "The new asset management: Implications of servitization in circular economy", Journal of Industrial Engineering and Management Science, Vol. 2018 No. 1, pp. 109-120.

Electric vehicle batteries

European Commission (2015), "Closing the loop - an EU action plan for the circular economy", available at: https://eur-lex.europa.eu/legal-content/EN/TXT/?uri=CELEX\%3A52015DC0614 (accessed 26 February 2020).

European Commission (2018), "Report on raw material for battery applications", available at: https://ec. europa.eu/commission/sites/beta-political/files/report-building-strategic-battery-value-chainapril2019_en.pdf (accessed 26 February 2020).

European Commission (2019), "Commission publishes evaluation of the EU batteries directive European commission", available at: https://ec.europa.eu/info/news/commission-publishesevaluation-eu-batteries-directive-2019-apr-09-0_en (accessed 21 February 2020).

Hill, N., Clarke, D., Blair, L. and Menadue, H. (2019), "Circular economy perspectives for the management of batteries used in electric vehicles 'European commission draft project report”, Public Office of the European Union, doi: 10.2760/537140 (accessed 20 December 2019).

Hirst, D., Butcher, L. and Hinson, S. (2018), "Electric vehicles and infrastructure", House of Commons Library, doi: 10.1007/978-3-540-33037-0_13.

Hou, L. (2019), "New guidelines regulate battery recycling sector", China Daily, available at: www. chinadaily.com.cn/a/201905/20/WS5ce1f286a3104842260bc865.html\%3E (accessed 20 December 2019).

International Energy Agency (2018), “Global EV outlook 2018”, available at: https://webstore.iea.org/ global-ev-outlook-2018 (accessed 17 February 2020).

Jolly, J. (2020), "UK could ban sale of petrol and diesel cars in 12 years, says Shapps", The Guardian, available at: www.theguardian.com/environment/2020/feb/12/uk-ban-sale-petrol-diesel-cars-shappstransport (accessed 23 February 2020).

Kampker, A. (2016), "Evaluation of a remanufacturing for lithium ion batteries from electric cars", International Journal of Mechanical and Mechatronics Engineering, Vol. 10 No. 12, pp. 1922-1928.

Lee, R. and Stokes, E. (2008), "Rehabilitating the definition of waste: is it fully recovered?", YEEL, Vol. 162, pp. 179-180.

Loughran, J. (2018), "Japan's first electric car battery recycling plant to sell old batteries at half price", Engineering and Technology, available at: https:/eandt.theiet.org/content/articles/2018/03/japan-sfirst-electric-car-battery-recycling-plant-to-sell-old-batteries-at-half-price/ (accessed 5 June 2020).

Melin, H.E (2018), "The Lithium-Ion battery end-of-Life market 2018-2025”, available at: www3.weforum. org/docs/GBA_EOL_baseline_Circular_Energy_Storage.pdf (accessed 26 February 2020).

National Grid (2018), "Future energy scenarios system operator", available at: http://fes.nationalgrid. com/media/1363/fes-interactive-version-final.pdf (accessed 20 February 2020).

Neely, N. (2007), "Exploring the financial consequences of servitisation of manufacturing", Operations Management Research, Vol. 1 No. 2, pp. 103-118.

Office for Low Emission Vehicles (2015), "Uptake of ultra low emission vehicles in the UK", available at: https:/assets.publishing.service.gov.uk/government/uploads/system/uploads/attachment_data/ file/464763/uptake-of-ulev-uk.pdf (accessed 12 June 2020).

Paris Agreement to the United Nations Framework Convention on Climate Change (2015), available at: https:/unfccc.int/files/essential_background/convention/application/pdf/english_paris_agreement. pdf (accessed 27 February 2020).

Sacciani, N. (2012), "Servitisation strategies and sourcing decisions for product services: an exploratory study", International Journal of Industrial and Systems Engineering, Vol. 10 No. 3, pp. 336-354.

Spears, J. (2015), "Electric vehicles and critical metals", SETIS Magazine, No. 8, p. 14. 
JPPEL 12,3

Spring, M. and Araujo, L. (2017), "Product biographies in servitization and the circular economy", Industrial Marketing Management, Vol. 60, pp. 126-137.

Trafigura Research Report (2018), "Meeting the EV challenge: responsible sourcing in the electric vehicle battery", available at: www.trafigura.com/brochure/meeting-the-evchallenge-responsible-sourcing-in-the-electric-vehicle-battery-supply-chain (accessed 15 February 2020).

Tytgat, J. (2013), "The recycling efficiency of Li-ion EV batteries according to the EC regulation, and the relation with the end-of-life vehicles directive recycling rate", World Electric Vehicle Journal, Vol. 6 No. 4, p. 1039.

Tytgat, J. and Tomboy, W. (2017), “New insights into residual value: RECHARGE perspective”, 5th E-Mobility Stateholder Forum.

Zhao, S., Li, G., He, W., Huang, J. and Zhu, H. (2019), "Recovery methods and regulation status of waste lithium-ion batteries in China: a mini review", Waste Management and Research, Vol. 37 No. 11, pp. 1142-1152.

\section{Further reading}

Department of Environment Food and Rural Affairs (2018), "Our waste, our resources: a strategy for England", HM Goverment.

Directive 2000/53/EC of the European Parliament and of the Council of 18th September 2000 on end-of life vehicles OJ L 269/1.

Directive 2006/66/EC of the European Parliament and of the Council of 6th September 2006 on batteries and accumulators and waste batteries and accumulators and repealing Directive 91/157/EEC OJ $266 / 1$.

Directive 2008/98/EC of the European Parliament and of the Council of 19 November 2008 on waste and repealing certain Directives OJ L 312.

Directive 2018/851 of the European Parliament and of the Council of 30 May 2018 amending Directive 2008/98/EC on waste OJ L 150.

Faraday Institution, ReLiB project (2020), "Recycling and reuse", available at: https://faraday.ac.uk/ research/lithium-ion/recycle-reuse (accessed 25 February 2020).

Regulation (EC) No 1907/2006 of the European Parliament and of the Council of 18 December 2006 concerning the Registration, Evaluation, Authorisation and Restriction of Chemicals (REACH), establishing a European Chemicals Agency, amending Directive 1999/45/EC and repealing Council Regulation (EEC) No 793/93 and Commission Regulation (EC) No 1488/94 as well as Council Directive 76/769/EEC and Commission Directives 91/155/EEC, 93/67/EEC, 93/105/EC and $2000 / 21 /$ EC.

Report from the Commission (2017), Report from the Commission to the European Parliament, the Council, the European Economic and Social Committee and the Committee of the Regions on the Implementation of Directive 2000/53/EC on End-Of-Life Vehicles for the periods 2008-2011 and 2011-2014; COM(2017) 98 final.

\section{Corresponding author}

Jyoti Ahuja can be contacted at: j.ahuja@bham.ac.uk

For instructions on how to order reprints of this article, please visit our website: 